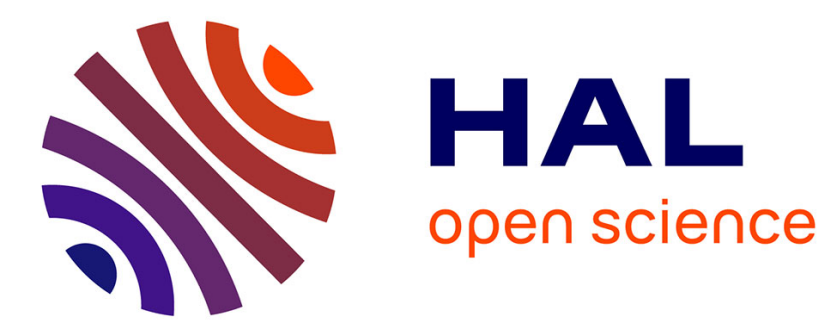

\title{
Cyclic behaviour simulation of X38CRMOV5-47HRC (AISI H11)-tempered martensitic hot-work tool steel
}

\author{
Z. Ahmer, Vincent Velay, Gérard Bernhart, Farhad Rezai-Aria
}

\section{To cite this version:}

Z. Ahmer, Vincent Velay, Gérard Bernhart, Farhad Rezai-Aria. Cyclic behaviour simulation of X38CRMOV5-47HRC (AISI H11)-tempered martensitic hot-work tool steel. International Journal of Microstructure and Materials Properties, 2008, 3 (2/3), pp.326-335. 10.1504/IJMMP.2008.018738 . hal-02136921

\section{HAL Id: hal-02136921 https://imt-mines-albi.hal.science/hal-02136921}

Submitted on 6 Nov 2019

HAL is a multi-disciplinary open access archive for the deposit and dissemination of scientific research documents, whether they are published or not. The documents may come from teaching and research institutions in France or abroad, or from public or private research centers.
L'archive ouverte pluridisciplinaire HAL, est destinée au dépôt et à la diffusion de documents scientifiques de niveau recherche, publiés ou non, émanant des établissements d'enseignement et de recherche français ou étrangers, des laboratoires publics ou privés. 


\title{
Cyclic behaviour simulation of X38CRMOV5-47HRC (AISI H11)-tempered martensitic hot-work tool steel
}

\author{
Z. Ahmer*, V. Velay, G. Bernhart \\ and F. Rézaï-Aria
}

Ecole Mines Albi, CROMeP, France

E-mail: zeeshan.ahmer@enstimac.fr

E-mail: vincent.velay@enstimac.fr

E-mail: bernhart@enstimac.fr

E-mail: rezai@enstimac.fr

*Corresponding author

\begin{abstract}
The cyclic behaviour of X38CrMoV5 (AISI H11) tool steel with a nominal hardness of $47 \mathrm{HRC}$ has been predicted. Basically, thermo-elastoplastic and thermo-elastoviscoplastic constitutive laws are investigated. First, various uniaxial isothermal conditions (LCF) with different strain rate, strain amplitude and temperature level are investigated. Then the constitutive laws are examined under various TMF loading conditions. The simulated results by both the approaches are compared with experimental results in terms of stress-strain behaviour and cyclic softening. Some applications of the model for simulation of thermal fatigue sample are shown. Taking into consideration the results of this work, the goal is to further characterise the limitations of these constitutive laws under complex and severe loading conditions, i.e., under variable temperature, variable strain amplitude and thermal fatigue structural specimen.
\end{abstract}

Keywords: tempered martensitic steels; Low Cyclic Fatigue; LCF; Thermo-mechanical Fatigue; TMF; thermal fatigue; constitutive laws; behaviour modelling; numerical simulation; viscoplasticity.

Biographical notes: Zeeshan Ahmer received his BE degree in Mechanical Engineering from NED University, Karachi, Pakistan, and his Master of Science degree in Aeronautical Engineering from SUPAERO, Toulouse, France. He is currently a third year PhD student of Ecole des Mines de Paris and is continuing his research studies in CROMeP. His research subject is on the prediction of the mechanical behaviour of X38CrMoV5-47HRC (AISI $\mathrm{H} 11)$ under severe thermomechanical loading applied to thermal fatigue. $\mathrm{He}$ has presented a paper in the 7th International Tooling Conference in Italy in the year 2006.

Dr. Vincent Velay is an Associate Professor at CROMeP. He received his MS degree from Paul Sabatier University in Toulouse (Applied Mathematics) and his $\mathrm{PhD}$ degree in material science from the Ecole des Mines de Paris. The focus of his research is understanding and modelling behaviour of metallic materials in order to assess their lifetimes. His research is interdisciplinary and brings together the fields of numerical mechanics and material science. He is an Associate Professor at the Ecole des Mines d'Albi in France and a Researcher in the research centre on tools, materials and forming processes. 
Dr. Gérard Bernhart received his MS degree and $\mathrm{PhD}$ degree both in the field of applied mechanics. Currently, he is a Professor at the Ecole des Mines d'Albi-Carmaux. He is also the Director of the Research Centre on Tools Materials and Processes, Albi, France. His scientific topics include tool steel behaviour and damage. He has published a great number of scientific and technical papers in this research field. His current research interests focus on the composite processes.

Dr. Farhad Rézaï-Aria is a full Professor and the Head of the Tool Surface Investigations Research Unit at CROMeP. He obtained his BSc in Metallurgy Engineering from the Tehran University of Technology in 1976.He got his $\mathrm{PhD}$ in 1986 at the Materials Centre at École des Mines de Paris, France, on high-temperature isothermal and non-isothermal fatigue (thermal and thermomechanical) and oxidation interactions of cobalt- and nickel-based super alloys for turbine blade applications. From 1988 to 1996, he was an Assistant Professor in the high-temperature fatigue group at the Mechanical Metallurgy Laboratory, headed by Professor B. Ilschner, in the Swiss Federal Institute of Technology.

\section{Introduction}

Hot-working tools are of primary concern for industrial production and in particular mass production, i.e., high-pressure die casting, hot forging, stamping and rolling, etc. The hot-work tools are, in most cases, made of steels. The surface of tools is basically damaged by the cyclic and progressive process under transient temperature cycling, i.e., the process of non-isothermal fatigue. It results in alternating compressive and tensile stresses at the surface of the tool that arise from differential thermal expansion/contraction during sudden transient temperature changes (Rézaï-Aria, 2002; Velay et al., 2002a).

Hence the material demands an advanced modelling of its mechanical behaviour under such severe conditions. Depending upon the design and application philosophies and approaches, thermo-elastic, thermo-elastoplastic or thermo-elastoviscoplastic models can be used. However, the validity of such constitutive laws needs to be examined under several cyclic loading conditions. For the thermo-elastoplastic model, parameters are identified by several tensile tests performed at different temperature levels ranging from $20^{\circ} \mathrm{C}-600^{\circ} \mathrm{C}$. The constitutive thermo-elastoviscoplastic model includes kinematic and isotropic parts in order to consider the effects of strain rate, dynamic recovery and cyclic softening (Zhang et al., 2002; Velay et al., 2006).

The experimental database is briefly shown here. This database comprises tensile test, LCF and TMF tests, which have been carried out in the CROMeP laboratory. The research activities of Research Centre on Tools, Materials and Forming Processes (CROMeP) are focused towards optimisation of forming tools and dies. These topics are of high relevance for manufacturing industries and they require a multidisciplinary approach, in order to solve the underlying scientific and technical issues. The total staff is about 55 people, including seven professors, 12 assistant professors, six technicians, two administrative assistants and an average of 23 doctoral candidates and five masteral students. The main author of this article is a third year PhD student in CROMeP. 


\section{Material and experimental data}

The steel X38CrMoV5 (AISI H11) is regarded as a multipurpose material owing to its properties. It exhibits a high tensile strength at elevated temperatures, good fracture toughness ( $90 \mathrm{MPa} \sqrt{\mathrm{m}}$ for tempered martensite microstructure at room temperature) and good thermal conductivity $\left(\sim 26-29 \mathrm{~W} / \mathrm{m} . \mathrm{K}\right.$ at $\left.200^{\circ} \mathrm{C}-600^{\circ} \mathrm{C}\right)$, which makes it belong to the heat-resistant hot-work tool steels class. Owing to its chemical composition (Table 1) and subsequent microstructural changes during heat treatment (Table 2), X38CrMoV5 is regarded as a mechanical shock- and heat-resistant hot-work tool steel (Velay et al., 2002b; Velay et al., 2005).

\subsection{Chemical composition}

Table 1 Chemical composition (weight \%) of X38CrMoV5 steel (major alloying elements)

\begin{tabular}{lcccccccc}
\hline Steel & $C$ & $C r$ & $M n$ & $V$ & $N i$ & $M o$ & $S i$ & $F e$ \\
\hline X38CrMoV5 & 0.40 & 5.05 & 0.49 & 0.47 & 0.20 & 1.25 & 0.92 & bal \\
\hline
\end{tabular}

Source: Oudin (2001)

Table 2 Heat treatment procedure to achieve martensite microstructure for X38CrMoV5-47 HRC

\begin{tabular}{lcccc}
\hline Steel & Austenitisation & Ist tempering & 2nd tempering & Hardness \\
\hline X38CrMoV5 & $990^{\circ} \mathrm{C} / 1 \mathrm{~h} / \mathrm{air}$ & $550^{\circ} \mathrm{C} / 2 \mathrm{~h} / \mathrm{air}$ & $603^{\circ} \mathrm{C} / 2 \mathrm{~h} / \mathrm{air}$ & 47 \\
\hline
\end{tabular}

Source: Oudin (2001)

\subsection{Tensile test}

Tensile tests of the material with a nominal hardness of 47HRC are carried out at different temperature levels on a solid flat specimen from $200^{\circ} \mathrm{C}$ to $600^{\circ} \mathrm{C}$ to extract the thermomechanical and thermophysical properties of the material.

\subsection{Thermomechanical and thermophysical properties}

Table 3 represents the values of Thermal Expansion $(\alpha)$, Young Modulus (E), Ultimate Tensile Stress $(\sigma \mathrm{u})$, Conventional Yield Stress $\sigma 0.2$ (0.2\% strain offset), Poisson Ratio $(v)$, Density $(\rho)$, Thermal Conductivity $(\mathrm{K})$ and Specific Heat Capacity $(\mathrm{Cp})$ as a function of temperature (Rézaï-Aria, 2002; Zhang et al., 2002).

\subsection{LCF tests}

LCF experiments have been carried out on cylindrical test specimens at different temperature levels between $300^{\circ} \mathrm{C}$ and $600^{\circ} \mathrm{C}$ with different strain amplitudes; some of the test conditions are presented in Table 4. Symmetric tests have been carried out at strain rates of $10^{-2} / \mathrm{s}$ and $10^{-3} / \mathrm{s}$, whereas some tests are carried out with a relaxation time between $60 \mathrm{~s}$ to $90 \mathrm{~s}$, in tensile, double tensile and compressive phases at a strain rate of $10^{-3} / \mathrm{s}$ (Velay et al., 2006). 
Table 3 Thermophysical and thermomechanical properties of material X38CrMoV5

\begin{tabular}{lcccccc}
\hline$T^{\circ} \mathrm{C}$ & 20 & 200 & 300 & 400 & 500 & 600 \\
\hline$\alpha^{*} 1 \mathrm{E}-6$ & 13.5 & 13.6 & 13.7 & 13.9 & 14 & 14.2 \\
E (Mpa) & 213270 & 184734 & 178932 & 169836 & 153167 & 126243 \\
$\sigma \mathrm{u}(\mathrm{MPa})$ & 1460 & 1350 & 1290 & 1230 & 1060 & 815 \\
$\sigma 0.2(\mathrm{MPa})$ & 1200 & 1110 & 1065 & 1000 & 880 & 605 \\
$\nu$ & 0.30 & 0.30 & 0.30 & 0.30 & 0.30 & 0.30 \\
$\rho(\mathrm{Kg} / \mathrm{m} 3)$ & 7847 & 7789 & 7755 & 7718 & 7679 & 7639 \\
$\mathrm{~K}(\mathrm{w} / \mathrm{m} . \mathrm{K})$ & 29.8 & 31.8 & 32.1 & 31.8 & 30.9 & 29.4 \\
$\mathrm{Cp}(\mathrm{J} / \mathrm{Kg} . \mathrm{K})$ & 482 & 561 & 589 & 621 & 669 & 745 \\
\hline
\end{tabular}

\subsection{TMF tests}

TMF tests have also been performed on a tubular test specimen of X38CrMoV5-47HRC, at various temperature ranges (between $200^{\circ} \mathrm{C}-600^{\circ} \mathrm{C}$ ), heating and cooling time, mechanical strain amplitudes and rates (Velay et al., 2002b; Oudin, 2001).

Table 4 Representations of TMF test conditions

\begin{tabular}{lcccc}
\hline$\Delta \varepsilon m(\%)$ & $\operatorname{Tmin}-\operatorname{Tmax}\left({ }^{\circ} \mathrm{C}\right)$ & $t$ heat $(\mathrm{sec})$ & $t$ cool $(\mathrm{sec})$ & Period $(\mathrm{sec})$ \\
\hline 1.50 & $200-600$ & 100 & 130 & 230 \\
1.00 & $200-600$ & 100 & 140 & 240 \\
0.50 & $200-600$ & 100 & 140 & 240 \\
1.00 & $300-600$ & 75 & 85 & 160 \\
0.70 & $400-600$ & 50 & 50 & 100 \\
1.50 & $200-500$ & 75 & 115 & 190 \\
1.00 & $200-500$ & 75 & 110 & 185 \\
1.50 & $200-550$ & 88 & 138 & 226 \\
\hline
\end{tabular}

\section{Simulation}

Numerical simulations are performed by utilising two behaviour models, thermo-elastoplastic and thermo-elastoviscoplastic, which are briefly discussed as follows:

\subsection{Thermo-elastoplastic model}

For the mathematical thermo-elastoplastic numerical simulation, experimental data have been obtained after carrying out a tensile test (Figure 1) of a solid specimen at different temperatures (Medjedoub et al., 2003).

$$
\sigma(T)=f\left\{\varepsilon_{e l}(T)\right\} \text { with } \varepsilon_{p l}(T)=\varepsilon_{t o t}(T)-\varepsilon_{e l}(T)-\varepsilon_{t h}(T) .
$$




$$
\varepsilon_{e l}(T)=\sigma(T) / E(T) ; \varepsilon_{\text {mech }}(T)=\varepsilon_{e l}(T)+\varepsilon_{p l}(T) \text { and } \varepsilon_{t h}(T)=\alpha(T) \Delta T
$$

where:

$$
\begin{aligned}
\varepsilon_{e l} & =\text { elastic strain } \\
\varepsilon_{m e c h} & =\text { mechanical strain and } \varepsilon_{t h} \text { is thermal strain. }
\end{aligned}
$$

The thermo-elastoplastic model implemented in ABAQUS requires tensile tests results to be introduced by piece straight-line segments. The results in terms of the evolution of stress as a function of plastic strain at different temperatures have been further implemented in the ABAQUS 6.4 programme for simulation.

Figure 1 Results of tensile tests at different temperature levels

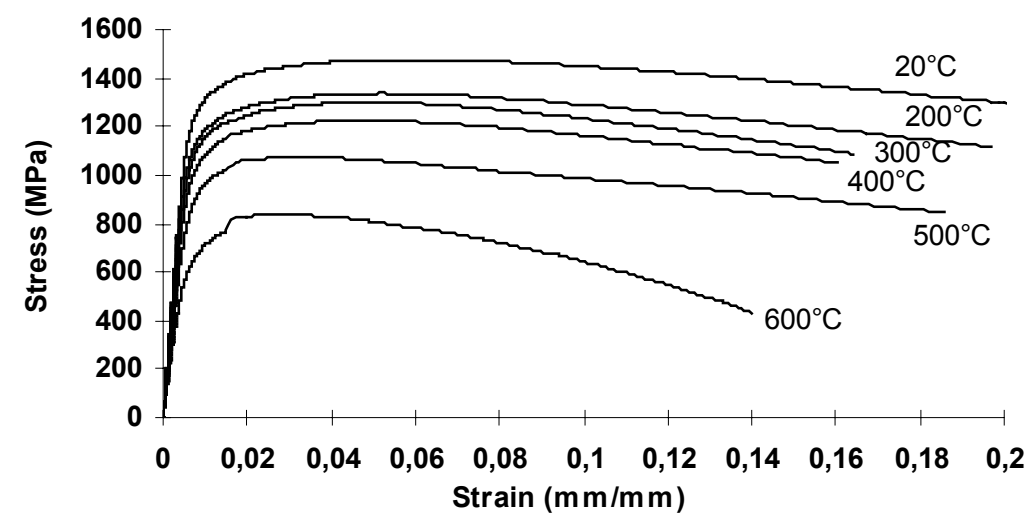

Source: Medjedoub et al. (2003)

\subsection{Thermo-elastoviscoplastic model formulation}

A constitutive Chaboche-type (Chaboche, 1986) model is utilised in our numerical simulation. This model is based on a unified viscoplastic approach considering the superposition of kinematic and isotropic hardening describing the cyclic hardening/ softening and Bauschinger effects.

In the model, it is postulated that the evolutions of the transient inelastic strain during each hysterises loop can be described through kinematic variables (Velay, 2003):

$$
X_{i}=\frac{C_{i}}{D_{i}} v\left(1-e^{-D_{i} v \varepsilon_{p}}\right) ; v= \pm 1 ; i=1,2
$$

$v=+1$; if $\varepsilon_{\mathrm{p}}>0$ and $v=-1$; if $\varepsilon_{\mathrm{p}}<0$.

The slow evolutions of the stress during the successive cycles to the (cyclic softening of the material) is reproduced through an isotropic hardening variable (drag stress) (Velay, 2003):

$$
R_{i}=Q_{i}\left(1-e^{-b_{i} p}\right) ; i=1,2
$$

$p$ is the cumulated plastic strain, which can be defined by: 
$\dot{p}=\dot{\varepsilon}_{p} \mid=\left\langle\frac{f}{K}\right\rangle^{n}$ where $f$ corresponds to the yield surface given as:

$$
f=\left|\sigma-\sum_{i=1}^{2} X_{i}\right|-\sum_{i=1}^{2} R_{i}-R_{0} .
$$

Finally,

$$
\sigma= \pm\left(\sigma_{v}+R_{1}+R_{2}+R_{0}\right)+X_{1}+X_{2}
$$

where:

$$
\sigma v=K \dot{\varepsilon}_{p}^{1 / n}=\text { viscous stress (i.e., strain rate-dependent) }
$$

$C_{i}, D_{i}, Q_{i}, b_{i}, K, n$ and $R_{0}=$ temperature-dependent material parameters

(Velay, 2003).

The identification has been carried out through a LCF test for temperatures between $20^{\circ} \mathrm{C}$ to $600^{\circ} \mathrm{C}$ with an amplitude of deformation of $\pm 0.8 \%$ and different strain rates $\left(\dot{\varepsilon}=10^{-4} s^{-1}, 10^{-3} s, 10^{-2} s^{-1}\right)$. These parameters have been validated with 1D formulation for each level of temperature (Velay, 2003).

\section{Discussion}

\subsection{LCF simulation}

All LCF test results have been simulated with the thermo-elastoviscoplastic formulation considering the same test conditions (Table 1), as cyclic softening cannot be simulated with the thermo-elastoplastic model. The simulated and experimental results are then further compared in terms of hysterisis loops and cyclic softening curves. Comparative results as hysterisis loops with relaxation in the compression phase and corresponding cyclic softening are shown in Figure 2.

Figure 2 (a) Comparative experimental hysteresis loop at $520^{\circ} \mathrm{C}$ with relaxation in tensile phase (b) Comparative experimental cyclic softening curve at $520^{\circ} \mathrm{C}$

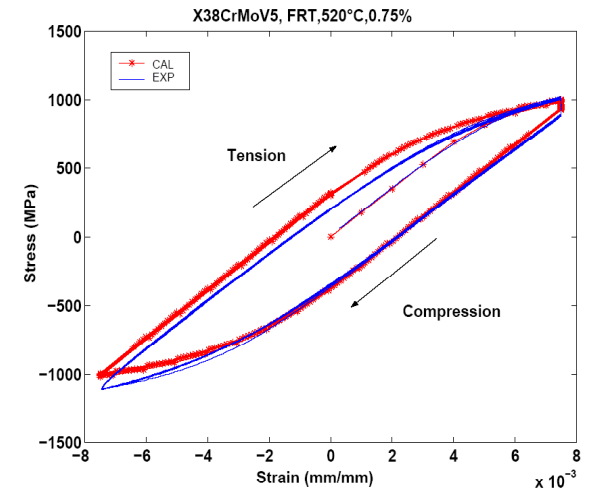

(a)

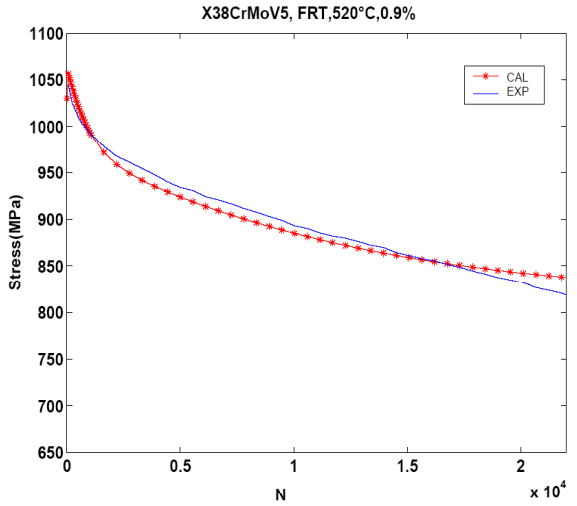

(b) 
Generally, for all the simulated test conditions (Table 1), the results show a good correspondence with the experimental results in terms of hysterises loops. Whereas for the comparison of cyclic softening curves, errors are calculated by the Euclidian norm method (Equation (7)) and are presented in Table 5.

$$
\frac{\|\sigma(\exp )-\sigma(\operatorname{sim})\|^{2}}{\|\sigma(\exp )\|^{2}} \text {. }
$$

In the above equation $\sigma(\exp )$ stands for the experimental value of stress, whereas $\sigma(\operatorname{sim})$ stands for the simulated (calculated) value of stress.

Table 5 Results of comparative experimental cyclic softening curves at each temperature

\begin{tabular}{lcccc}
\hline $\begin{array}{l}\text { Temperature } \\
\left({ }^{\circ} \mathrm{C}\right)\end{array}$ & $\Delta \varepsilon(\%)$ & $\dot{\varepsilon}\left(s^{-1}\right)$ & $\begin{array}{c}\text { Relaxation time } \\
(\mathrm{sec})\end{array}$ & $\begin{array}{c}\text { Euclidian norm } \\
(\%)\end{array}$ \\
\hline 500 & 0.5 & $2.10^{-2}$ & 0 & 14.40 \\
& 0.6 & $2.4 .10^{-2}$ & 0 & 14.35 \\
520 & 0.6 & $10^{-2}$ & 0 & 7.41 \\
520 & 0.75 & $10^{-3}$ & 0 & 5.85 \\
& 0.6 & $10^{-3}$ & 20 & 6.76 \\
520 & 0.75 & $10^{-3}$ & 20 & 4.68 \\
& 0.6 & $10^{-3}$ & 60 & 7.81 \\
\hline
\end{tabular}

Source: Velay (2003)

\subsection{TMF simulation}

TMF simulation is based on two models, thermo-elastoplastic and thermoelastoviscoplastic. The simulation is carried out for all the available test conditions (Table 4) (Velay et al., 2005; Medjedoub et al., 2003). Results of both models are compared with experimental results in terms of stress-mechanical strain loops. As a general interpretation of all the comparative results, we present in Figures 3(a-c), the results for the test conditions of $200^{\circ} \mathrm{C}-550^{\circ} \mathrm{C}$ with a strain amplitude of $1.5 \%$ and $200^{\circ} \mathrm{C}-600^{\circ} \mathrm{C}$ with a strain amplitude of $0.7 \%$ (thermo-elastoviscoplastic model), respectively.

For the test condition of $200^{\circ} \mathrm{C}-600^{\circ} \mathrm{C}$ with a strain amplitude of $0.7 \%$ (Figure 3c), it is shown that in the first heating phase both curves show normal behaviour till a bit before the end of first heating. After reaching Tmax, both curves show absolutely different results in all the remaining cycles. It is to be noted here that for the said test condition the value of Tmax is found to be $607^{\circ} \mathrm{C}$ experimentally, whereas $603^{\circ} \mathrm{C}$ is the temperature of the second tempering of material. During the experimental thermal cycles of these specimens, when temperature crosses $603^{\circ} \mathrm{C}$, a drastic microstructural change occurs in the material. Consequently the thermo-mechanical and thermo-physical properties change with respect to temperature. Whereas the thermo-elastoviscoplastic model has been developed in the hypothesis of structural stability. 
Figure 3 (a) $\mathrm{TMF} 200^{\circ} \mathrm{C}-550^{\circ} \mathrm{C}, \Delta \varepsilon_{m}=1.5 \%$, stress-mechanical strain comparison with the thermo-elastoviscoplastic model (b) TMF $200^{\circ} \mathrm{C}-550^{\circ} \mathrm{C}, \Delta \varepsilon_{m}=1.5 \%$, stressmechanical strain comparison with thermo-elastoplastic model (c) TMF $200^{\circ} \mathrm{C}-600^{\circ} \mathrm{C}$, $\Delta \varepsilon_{m}=0.7 \%$, stress-mechanical strain comparison with thermo-elastoviscoplastic model

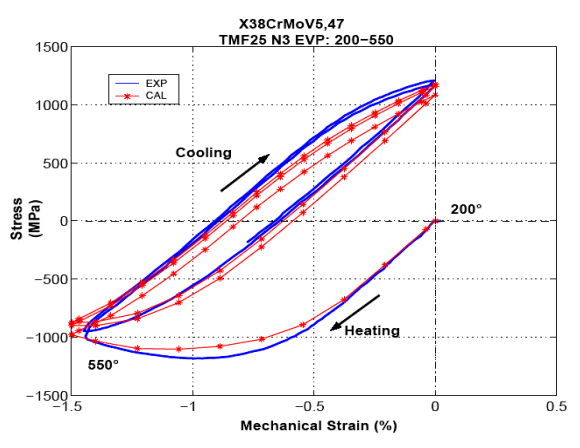

(a)

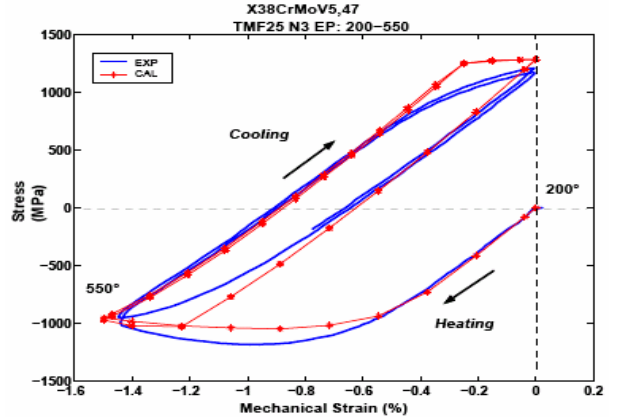

(b)

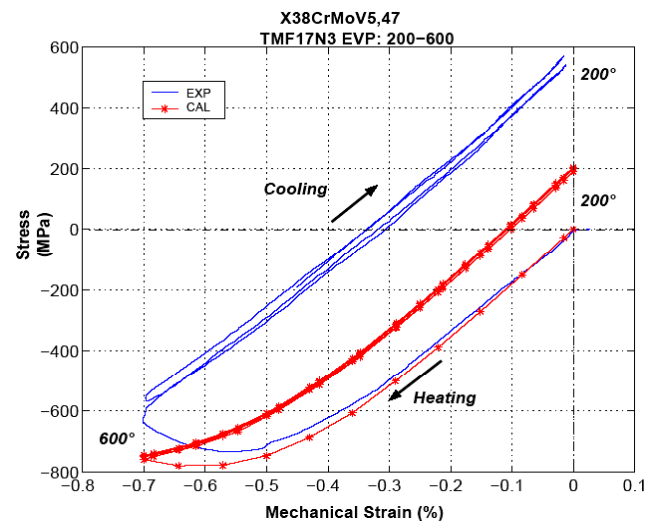

(c)

\subsection{TF simulation}

Thermo-mechanical simulations of tubular cylindrical thermal fatigue test specimen re carried out by using both the models. Thermo-elastoplastic simulations have already been carried out in the CROMeP Laboratory (Medjedoub et al., 2003). We recalculated these thermal and mechanical simulation for comparison with the results of thermo-elastoviscoplastic model. The experimental results are available in terms of temperature at several positions, i.e., at the surface and in-depth. These results are used to identify external and internal thermal boundary conditions by the implementation of a numerical simulation on ABAQUS 6.4.

The results of simulation with the thermo-elastoplastic model have been plotted in terms of stress as a function of mechanical strain and plastic strain (Figures 4a-b). In Figure 4(a), the same problem is observed in the hysterisis loop with the thermo-elastoplastic model, which has already been discussed in the previous section. The plotted results in terms of stress-plastic strain (Figure 4b) shows that with the thermo-elastoplastic model, plastic strain stabilises after two or three cycles; 
whereas, with thermo-elastoviscoplastic model (Figure 4d) plastic strain continues to accumulate for each cycle. The application of thermo-elastoviscoplastic model in terms of stress-mechanical strain loops, is shown in Figure 4(c).

Figure 4 (a) Calculated stress-strain loops using thermo-elastoplastic model (b) Calculated stress-plastic strain loops using thermo-elastoplastic model (c) Calculated stress-strain loops using thermo-elastoviscoplastic model (d) Calculated stress-plastic strain loop using thermo-elastoviscoplastic model

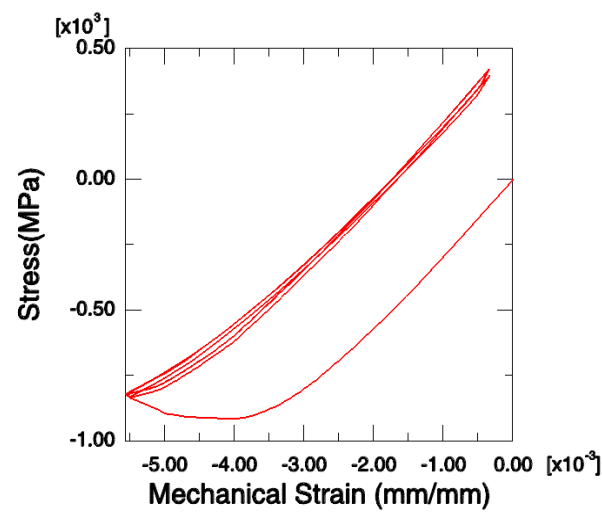

(a)

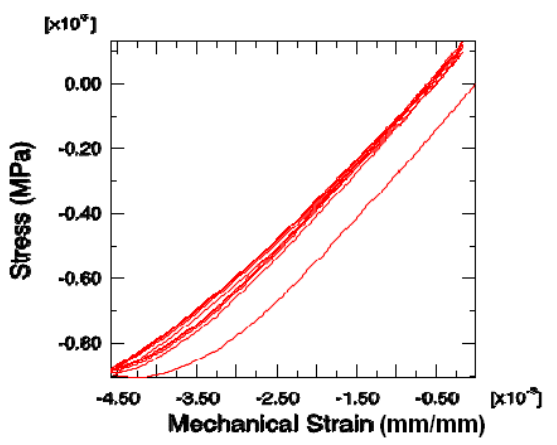

(c)

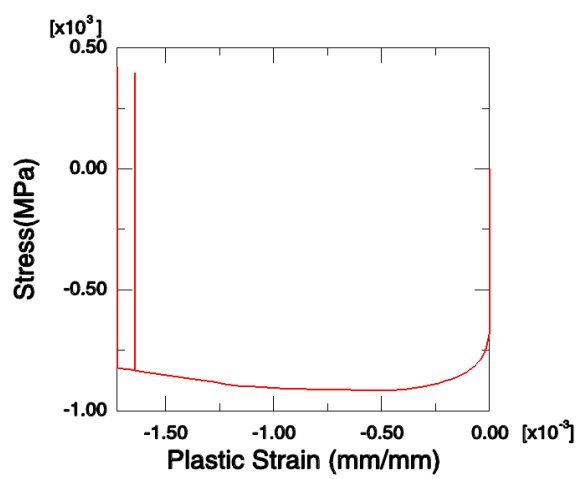

(b)

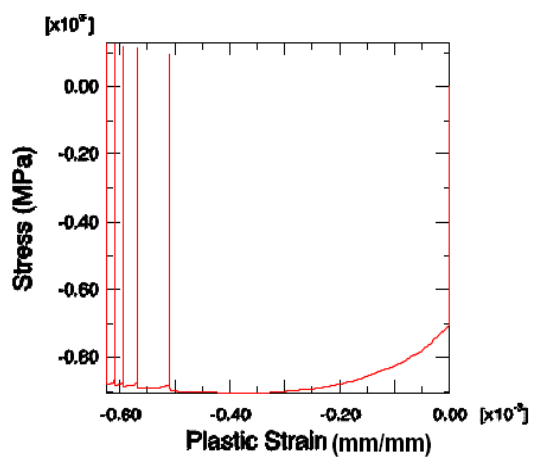

(d)

\section{Conclusion}

These numerical simulations have been carried out to predict the behaviour of the 47HRC H11 tool steel using thermo-elastoplastic and thermo-elastoviscoplastic (Chaboche-type model). These laws have been applied to a total of 66 LCF and TMF test conditions, which have been carried out on different lots of specimen. The comparative results are shown in terms of hysterises loops with LCF and TMF experiments. The thermoelastoplastic model is not able to predict cyclic-softening behaviour.

The thermo-elastoviscoplastic model has shown good comparative results for most of the LCF and TMF test conditions, but as discussed in the section of TMF simulation, it has shown a clear difference with the experimental result (Figure 3c) when the temperature exceeds $603^{\circ} \mathrm{C}$. We have considered a simplified thermo-elastoviscoplastic 
model without recovery. Whereas time recovery parameters become effective after $550^{\circ} \mathrm{C}$. For TMF tests, which are carried out at low strain rate, strain recovery parameters may become significant for an optimised validation of stress values. The microstructural behaviour of material will also be studied when Tmax exceeds $550^{\circ} \mathrm{C}$.

An application of models for the simulation of a thermal fatigue test specimen is also presented. The experimental data in this regard is not available owing to the limitations of measuring stress and mechanical strain in biaxial state. Work in this regard, specifically the development of a new thermal fatigue test bench is in progress to address the difficulties of measuring mechanical strain. Once it is achieved, it will be possible to apply and further validate these constitutive laws on a structural specimen.

\section{References}

Chaboche, J. (1986) 'Time dependant constitutive theories for cyclic plasticity', International Journal of Plasticity, Vol. 2.

Medjedoub, F., Le Roux, S., Dour, G., Rézaï-Aria, F., Hairy, P., Khang-Ny, H. and Golin, M. (2003) 'An investigation on thermal fatigue surface cracking of $5 \mathrm{CrMoV}$ die too steels', NADCA.

Oudin, A. (2001) 'Thermomechanical fatigue of hot work steels', CROMeP, PhD thesis.

Oudin, A., Lamesle, P., Penazzi, L. and Rézaï-Aria, F. (2001) 'Thermomechanical fatigue behaviour and life assessment of hot work tool steels', in L. Rémy and J. Petit (Eds.) Proceedings of Temperature-Fatigue Interaction of Ninth International Spring Meeting of SF2M, Elsevier, Paris: ESIS Publication, Vol. 29, pp.195-201.

Rézaï-Aria, F. (2002) 'Thermal fatigue of hot work tool steel', Proceedings 6th International Tooling Conference, Karlstad, Sweden, Vol. 2.

Velay, V. (2003) 'Modélisation du Comportement Cyclique de la durée de Vie d'Acier à Outils Martensitique', $\mathrm{PhD}$ thesis, CROMeP.

Velay, V., Bernhart, G., Delagnes, D. and Penazzi, L. (2005) 'A continum damage model applied to fatigue life time prediction of Martensitic tool steel', Fatigue and Fracture of Engineering Materials and Structures, Vol. 28, pp.1009-1023.

Velay, V., Bernhart, G. and Penazzi, L. (2006) 'Cyclic behaviour modelling of a tempered martensitic hot work tool steel', International Journal of Plasticity, Vol. 22, No. 3, pp.459-496.

Velay, V., Bernhart, G., Penazzi, L. and Zhang, Z. (2002a) 'Cyclic behaviour modelling of martensitic hot work tool steels', Proceedings CAMP 2002 - High-Temperature Fatigue, Paderborn, Germany, pp.64-75.

Velay, V., Persson, A., Bernhart, G., Bergstrom, J. and Pennazi, L. (2002b) 'Thermal fatigue of tool steels: experiment and numerical simulation', Proceedings 6th International Tooling Conference, Karlstad, Sweden, Vol. 2, pp.667-685.

Zhang, Z., Delagnes, D. and Bernhart, G. (2002) 'Anisothermal cyclic plasticity modeling of Martensitic steels’, International Journal of Fatigue, Vol. 4, No. 6, pp.635-648. 